\title{
Identification and mapping of real acupoints in the anatomical topography of Boa constrictor
}

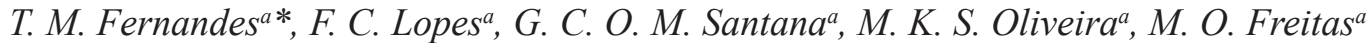 \\ and C. I. A. Freitas ${ }^{a}$
}

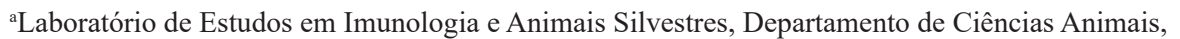 \\ Universidade Federal Rural do Semi-Árido - UFERSA, BR 110, Km 47, Bairro Presidente Costa e Silva, \\ CEP 59625-900, Mossoró, RN, Brasil \\ *e-mail: tmelofernandes@yahoo.com.br
}

Received: May 7, 2017 - Accepted: September 29, 2017 - Distributed: May 31, 2019

(With 2 figures)

\begin{abstract}
Acupuncture is a therapy of the traditional Chinese medicine technique, which over the years has been widespread in the West. Defined as a needle-point treatment technique (acupoints), exactly preconfigured in the body to produce a specific physiological reaction to restore the balance between the function of conflicting states and homeostasis, alternating states of energy and thus maintain the ideal organ and body organization. Thus, the objective of this study was to map and describe the main points of acupuncture in the species Boa constrictor, and their indications to promote the balance of this species. The unprecedented result of the mapping was the discovery of specific acupoints with individual location indications without distribution in specific meridians and dispersedly distributed in the body.
\end{abstract}

Keywords: wildanimals, acupoints, mapping, Boa constrictor.

\section{Identificação e mapeamento de acupontos reais na topografia anatômica de Boa constrictor}

\begin{abstract}
Resumo
A acupuntura é uma técnica terapêutica da Medicina Tradicional Chinesa, que ao longo dos anos tem sido muito difundida no Ocidente. Definida como uma técnica de tratamento com inserção de agulhas em pontos (acupontos) exatamente pré-estabelecidos sobre o organismo, para produzir uma reação fisiológica específica com o intuito de restabelecer o equilíbrio entre estados contraditórios de função e a homeostase, alternando os estados de energia e com isto mantendo a organização do órgão e do organismo. Com isso, o objetivo do presente trabalho foi mapear e descrever os principais pontos de acupuntura nas espécies Boa constrictore suas indicações para promover o equilíbrio dessa espécie. O resultado inédito do mapeamento foi à descoberta de pontos de acupuntura específicos com indicações de localização individuais sem distribuição em meridianos específicos e dispersamente distribuídos no corpo.
\end{abstract}

Palavras-chave: animais silvestres, acupontos, mapeamento, jibóia.

\section{Introduction}

Acupuncture is characterized as a technique that uses physical (needle, laser) and chemical (acuity) stimuli in defined areas of the skin for therapy and diagnosis of reversible functional diseases as well as for the treatment of serious diseases (Ribeiro, 2013; Draehmpaehl and Zohmann, 1997).

The word acupuncture is derived from the Latin accent and pungere radicals, meaning needle and pierce (Serpa et al., 2016; Draehmpaehl and Zohmann, 1997). With the development of mankind as acupuncture techniques have evolved. In the beginning as acupuncture needles were made of stone, they are made of silver, gold and stainless steel alloys (Wen, 2004).
For thousands of years in China Veterinary acupuncture has been applied as a result of the close relationship between the Chinese and riding horses, as well as water buffaloes used in agricultural tasks (Shoen, 2006). Then expanded to Japan, Korea and other parts of Asia (Xia and Wu, 2010).

It is based on traditional Chinese medicine which considers health the result of energy balance (Qi), divided into polarities (Yin / Yang), which compose it and sustain life, considers the human being as an integral being, without barriers between mind, body and spirit (Dalcin et al., 2016).

The place of application of the acupuncture technique on the surface of the body called acupoint or acupuncture point (Yang et al., 2014; Wen, 2008). Acupuncture is a 
structural and functional basis for an effective acupuncture treatment and is the place where the organs and organs of the body carry Qi to a surface of the body (Li, 2003).

Many researches suggest that acupuncture signaling is mainly transmitted by somatic sensory nerves, with afferent fibers of the sympathetic nerves involved in acupuncture points (Li, 2003; Zhang and Jin, 2012). The goal of acupuncture is to rebalance energy through channels that are distributed in the body through which the energy passes.

In the scientific literature, its mechanisms of action and its differentiation among the various acupuncture points of wild animals are still unknown. This work has much relevance due to the number of acupoints found, with the most diverse purposes, that reinforce its importance in Traditional Chinese Medicine.

\section{Material and Methods}

\subsection{Experimental design}

To determine the acupoints, five animals of the Boa constrictor species were used, which were under the care of the research laboratory of the Federal Rural Semi-Arid Federal University (UFERSA), adults and both sexes. The animals were monitored for 15 days before the experiment started, without solid fasting and without water restriction.

Heart rate (HR), respiratory rate (RF), temperature and glucose, to serve as a case parameter occurrence. HR was obtained by counting heart rate. RF was generally obtained by observing the thoracic expansion movements in one minute, a temperature to be measured using a digital infrared thermometer and a glucose meter with a blood glucose meter on a portable glycoside On call Plus), the test is based on the measurement of the electric current generated by the glucose reaction with the reagent from the test strip. The meter has a current and does not display the corresponding at the glucose level. The intensity of the current produced depends on the amount of glucose present in the blood sample.

The study was performed within ethical standards, with the number of animals and an intensity of the stimuli used to identify the acupoints.

In order to facilitate the identification of the location, the points were numbered sequentially following a head-tail calculation. Information on its location, technique and clinical indications are presented at each of the points described.

Clinical techniques and indications are suggested by correspondents of other species, who depend often are structured in an acupuncture work, sometimes accurate, others are general, showing that an acupuncture is a specific reflection on the quality as Topographic projections have as more important functions (Rubin, 1983).

\subsection{Animal containment}

The containment for Boa Constrictor was rapid, since a kind of elongated body and absence of thoracic and pelvic limbs, taking directly behind the head, preventing it from turning. When needed a hook logo was used after a head to press the animal against the ground. Always with less than three people, as a security measure, a hand force, a holding a head, a forefinger and a thumb held a jaw and two other things.

\subsection{Identification of acupoints and impedance}

Use of the electrostimulator and location of EL points $30-10 / 100 \mathrm{~Hz}$ NKL points of Brazilian origin. The EL30 is an electronic device that is intended exclusively for non-invasive applications in the technique called electro-acupuncture. It was conceived as a point detection instrument, where an electrostimulation therapy, used in different media with a purpose of detection and determination of qualities as stimulus conditions for different species and for different points.

It was traversed with an exploratory tip of the animal's body points to an occurrence of an audible signal indicating the localized point and an impedance. The sensitivity controller has been adjusted to find a better setting.

\section{Results}

A total of eight acupoints were identified and mapped in the $B$. constrictor species, with six acupoints in the cephalic region, one in the trunk region and one in the tail region.

\subsection{Acuponto 1}

B. constrictor acupoint 1 was identified in the region of the head below the eye and above the commissure of the lips. The technique selected was the insertion without rotation of a thin round needle, with a thickness of $4 \mathrm{~mm}$ at an angle of $45^{\circ}$, a degree of light difficulty for stimulation of this acupoint, impedance $5,000 \Omega$. The indication of the literature is to combat conjunctivitis, keratitis and problems of motor coordination (Figure 1).

\subsection{Acuponto 2}

The acupuncture 2 of $B$. constrictor was identified in the rostral region of the head, near the loreal fossa. The technique selected was the insertion without rotation of thin round needle, with $5 \mathrm{~mm}$ of thickness, with moderate

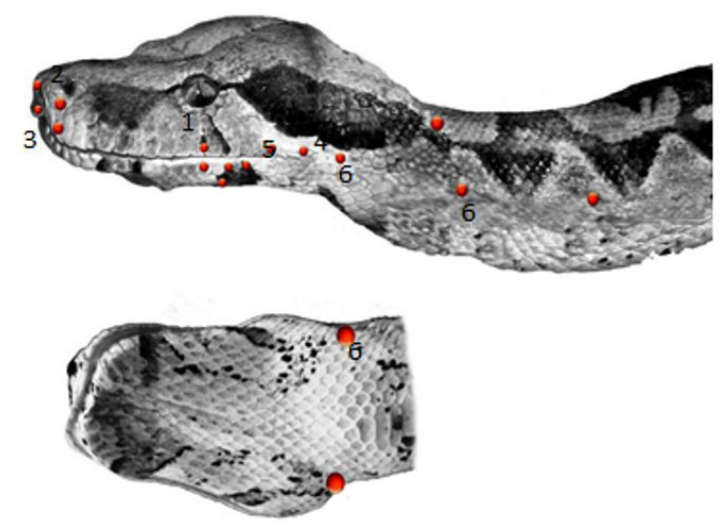

Figure 1. Head and neck acupoints of B. constrictor. 
degree of difficulty for stimulation of this acupoint, $1,500 \Omega$ impedance. The indication of the literature is to combat nasal congestion and rhinitis (Figure 1).

\subsection{Acuponto 3}

The acuponto 3 of $B$. constrictor was identified in the head, in the center of the rostral region, below the nostrils. The technique selected was the perpendicular insertion without rotation of thin round needle, with $3 \mathrm{~mm}$ of thickness, with degree of severe difficulty for stimulation of this acupoint, impedance $1,500 \Omega$. In the literature it is observed that they are indicated for shock, coma and cardiorespiratory arrest (Figure 1).

\subsection{Acuponto 4}

The acupoint 4 of $B$. constrictor was identified in the head, in the region anterior to the labial commissure. The technique selected was the insertion without rotation of thin round needle, with $4 \mathrm{~mm}$ of thickness, occurring a moderate degree of difficulty for stimulation of this acupoint, $1,000 \Omega$ impedance. In the literature it is observed that they are indicated for facial paralysis, edema and dental diseases (Figure 1).

\subsection{Acuponto 5}

Acupuncture 5 of $B$. constrictor was identified on the head at the end of the lower lip. The technique selected was the insertion without rotation of thin round needle, with $3 \mathrm{~mm}$ of thickness, occurring a degree of light difficulty for stimulation of this acupoint, 5,500 $\Omega$ impedance. The indication of the literature is to combat glossitis and edema (Figure 1).

\subsection{Acuponto 6}

Acupuncture 6 of $B$. constrictor was identified in the head and neck, region 11 to $13 \mathrm{~cm}$ from the tip of the rostral region of an adult animal in the lateral phase. The technique selected was the insertion without rotation of thin round needle, with $3 \mathrm{~mm}$ of thickness, occurring a degree of light difficulty for stimulation of this acupoint, impedance $4,000 \Omega$. In the literature it is observed that they are indicated for inflammations, rheumatism in the region of the neck, pains, dysphagia and edema (Figure 1).

\subsection{Acuponto 7}

The acupuncture 7 of $B$. constrictor was identified in the region of the trunk, in the dorsal position, on the intestine. The technique selected was the insertion without rotation of thin round needle, with $3 \mathrm{~mm}$ of thickness occurring a degree of light difficulty for stimulation of this acupoint, impedance $4,000 \Omega$. The indication of the literature is to combat constipation, intestinal spasms and intestinal dilatation (Figure 2).

\subsection{Acuponto 8}

The acupuncture 8 of $B$. constrictor was identified in the subcaudal region on the anal plate, near the anal orifice. The technique selected was the insertion without rotation of thin round needle, with $3 \mathrm{~mm}$ of thickness, occurring a

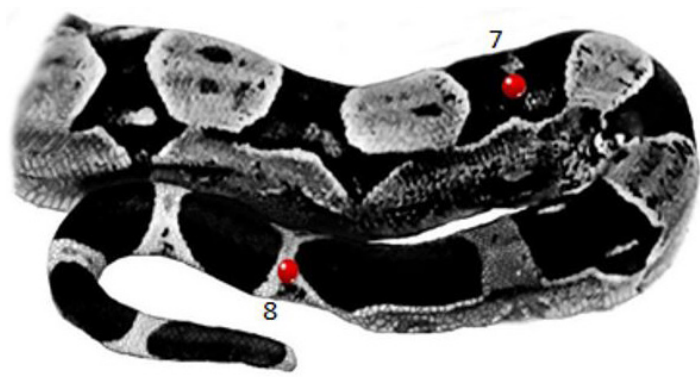

Figure 2. Dorsal region of the intestine and subcaudal region, near the anal orifice.

degree of light difficulty for stimulation of this acupoint, $2,500 \Omega$ impedance. In the literature it is observed that they are indicated for facilitating rectal relaxation, rectal inflammation, anal sphincter incontinence, intestinal colic, rectal surgery and edema (Figure 2).

\section{Discussion}

Acupuncture has been used for the treatment of several pathologies, is a safe, effective, simple, non-invasive and low cost technique. Excellent results have been obtained, proving the effectiveness of this specialty as an alternative in diseases. The use of this age-old therapy has contributed to helping clinicians solve problems that are not being achieved in everyday life through the path of common medicine (Silva and Vianna, 2011). Also acupuncture is a form of diagnosis since the study in wild animals is limited.

In acupuncture pain is the result of a condition of excess or deficiency of Qi or blood, and acupuncture regularizes these states (Mittleman and Gaynor, 2000). Most of the points found are associated with the treatment of pain and discomfort.

When acupuncture stimulation is applied at the correct points, neural impulses are received in the dorsal horn of the spinal cord. These impulses are driven to a variety of fibers for the spinal-articular and spinae-spermal tracts, projecting to the midbrain where they directly influence serotonergic pathways (Scott and Scott, 1997).

Most acupuncture points are located near peripheral nerves or their bifurcations, neuromuscular junctions, blood vessels and ligaments, this contributes to their low electrical resistance in the skin and conduction of energy.

The mechanisms of action proposed for the therapeutic effects of acupuncture are based on the principle of maintaining or recovering homeostasis. Recently, many efforts were made to establish the properties and characteristics of these mechanisms in terms of neuroanatomy, neurophysiology and neurochemistry (Kim et al., 2003; Guimarães et al., 1997).

According to Schwartz (2006), the diagnostic points when being palpated and presenting sensitivity reactions may indicate imbalance in the related visceral organs. This sensitivity can be manifested by the animal through various reactions such as: skin wrinkling; Movements 
with the head toward the point being palpated; Try to bite or show apathy.

The detection of points at specific times, that is, certain points are more active at certain times than others. Depending on the time analyzed, the detection becomes smaller or not found.

The detectability of some points when repeated in different days and times were not as easy as these to be found by the device, having eliminated the possibility of being battery problems of the device, firstly by the sensor of charge did not accuse anything and by the substitution nevertheless New, thus constituting a temporal effect. This may be physiological, such as a circadian rhythm or pathological manifestations, so that in the future it can be studied and constituted in a diagnostic tool.

Another possibility could be attributed to the Channel and Collateral System, which has the function of promoting connections between organs (Zang) and viscera $(\mathrm{Fu})$, communicating these two with tissues and sensorial organs at the extremities of the body, regulating the function of each Part of the body, and thus maintaining the balance between the Yin and Yang which can be translated as the complementarity of the Exterior and the Interior, Up and Down or Right and Left. In these channels we have closely interconnected physiologically and inseparably, the Energy (Qi) and the Blood (Xue) that circulates by the force of the Qi. The energetic channels and collagens carrying both Qi and Xue by the vessels (Mai) constitute the Jing Lu, the channels (Jing) and their secondary or collateral vessels (Luo). Although Qi is the dynamic force for Mai, where Xue is, Mai is the network that limits and directs the movements of the two, and thus the rhythmic pulsations in the movement of substances in the vessels can be affected by imbalances and depending on the degree, Diseases (Junying, 1996).

The existence of Acupuncture points has been investigated in several ways, among them the study of the electrical properties of the skin. Some points may not have been detected due to the impedance beyond the upper limits of the apparatus, which leads to question the form and depth of stimulation of the acupoints or even by the use of transpositional information only in order to improve the effectiveness or optimization of the treatment.

Analyzing interspecific factors, we would have alterations of position, shape, absence of structures, sintopia. One that should be emphasized would be the asymmetry that is found in ophidians as to the elongated form of organs or, anatomical differences such as the occurrence of lungs, air sacs or both, one on each side, are possible sources of variation in this species. Not being able to leave without considering yet another level, intraspecific, the individual differences (Junying, 1996).

Nevertheless, the identification and mapping of acupoints is extremely important, since the association of acupuncture with conventional treatments is a point of great importance, since it guarantees the potentialization of the treatment resulting from the synergism between both. It complements the resources of Western medicine and provides a more complete and solid framework for veterinary medicine therapeutics in wild animals.

\section{Conclusion}

The identification and mapping of acupuncture points are essential for advancing this technique of traditional Chinese medicine and new studies have emerged on other species of wild animals.

\section{References}

DALCIN, M.F., ALVES, F.C. and SALVI, J.O., 2016. The use of acupuncture in the treatment of Systemic Lupus Erythematosus:case report. Arch Health Invest., vol. 5, no. 5, pp. 280-285.

DRAEHMPAEHL, D. and ZOHMANN, A., 1997. Acupuntura no cão e no gato: princípios básicos e prática cientifica. São Paulo: Roca, 245 p.

GUIMARÃES, C.M., PINGE, M.C.M., YAMAMURA, Y. and MELLO, L.E.A.M., 1997. Effects of acupuncture on behavioral, cardiovascular and hormonal responses inrestraint stressed Wistar rats. Brazilian Journal of Medical and Biological Research, vol. 30, no. 12, pp. 1445-1450. http://dx.doi.org/10.1590/S0100879X1997001200011. PMid:9686165.

JUNYING, G., 1996. Medicina tradicional chinesa prática e farmacologia: teorias e princípios básicos. 1a ed. São Paulo: Rocca Editora.

KIM, H.-W., KWON, Y.-B., HAM, T.-W., ROH, D.-H., YOON, S.-Y., LEE, H.-J., HAN, H.-J., YANG, I.-S., BEITZ, A.J. and LEE, J.H., 2003. Acupoint stimulation using bee venom attenuates formalininduced pain behavior and spinal cord fos expression in rats. The Journal of Veterinary Medical Science., vol. 65, no. 3, pp. 349-355. http://dx.doi.org/10.1292/jvms.65.349. PMid:12679565.

LI, Z.R., 2003. Experimental acupuncture science. China Press of Traditional Chinese Medicine, vol. 327, pp. 146.

MITTLEMAN, E. and GAYNOR, J.S., 2000. A brief overview of the analgesic and immunologic effects of acupuncture in domestic animals. Journal of the American Veterinary Medical Association, vol. 217, no. 8, pp. 1201-1205. http://dx.doi. org/10.2460/javma.2000.217.1201. PMid:11043693.

RIBEIRO, V.G., 2013. Mapeamento dos pontos extras de acupuntura em cães. Belo Horizonte: Instituto Homeopático Jacqueline Pecker, 42 p. Monografia de Especialização em Acupuntura Veterinária.

RUBIN, M., 1983. Manual de acupuntura veterinária. São Paulo: Andrei. 159 p.

SCHWARTZ, C., 2006. Diagnóstico pela medicina tradicional chinesa em pequenos animais. In: A. SHOEN, ed. Acupuntura veterinária: da arte antiga à medicina moderna. $2 \mathrm{a}$ ed. São Paulo: Roca, pp. 147-158.

SCOTT S., SCOTT W.N., 1997. A biochemical hypothesis for the effectiveness of acupuncture in the treatment of substance abuse: acupuncture and the reward cascade. American Journal of Acupuncture, v. 25, n. 1, pp. 33-38

SERPA, L.S., WATANABE, L.A.R. and CARVALHO, A.L., 2016. Acupuncture in organs and viscera through of points Bei Shu: a literature review. Revista Amazônia Science \& Health, 
vol. 4, no. 1, pp. 35-40. http://dx.doi.org/10.18606/2318-1419/ amazonia.sci.health

SHOEN, A., 2006. Acupuntura veterinária: da arte antiga à medicina moderna. 2nd ed. São Paulo: Roca.

SILVA, P.H.P.S. and VIANNA, L.R., 2011. Princípios básicos da acupuntura veterinária: revisão de literatura. Revista Veterinária e Zootecnia em Minas, vol. 22, pp. 29-35.

WEN, T.S., 2004. Acupuntura clássica chinesa. 16a ed. São Paulo: Editora Cultrix.

WEN, T.S., 2008. Manual terapêutico de acupuntura. São Paulo: Editora Manole.
XIA, Y. and WU, G., 2010. Acupuncture therapy for neurological diseases: a neurobiological view. Heidelberg: Springer Verlag. http://dx.doi.org/10.1007/978-3-642-10857-0.

YANG, Q., XIE, Y.D., ZHANG, M.X., HUANG, B., ZHANG, C., LI, H.Y., ZHANG, R., QIN, M., HUANG, Y.X., WANG, J.J., 2014. Effect of electroacupuncture stimulation at Zusanli acupoint (ST36) on gastric motility: possible through PKC and MAPK signal transduction pathways. BMC Complementary and Alternative Medicine, vol. 14, no. 137, pp. 1-8

ZHANG, X. and JIN, G., 2012. Neurogenesis in adult hippocampus. In: T. SUN, ed. Neural stem cells and therapy. London: InTech, pp. 31-58. http://dx.doi.org/10.5772/29983. 